\title{
Operation of Norwegian Hydropower Plants and Its Effect on Block Fall Events in Unlined Pressure Tunnels and Shafts
}

\author{
Bibek Neupane ${ }^{1, *}$, Kaspar Vereide ${ }^{2}(\mathbb{D})$ and Krishna Kanta Panthi ${ }^{1}$ \\ 1 Department of Geoscience and Petroleum, Norwegian University of Science and Technology (NTNU), \\ Petroleumsteknisk Senter, F 410, Valgrinda, S.P Andersens Vei 15a, 7031 Trondheim, Norway; \\ krishna.panthi@ntnu.no \\ 2 Department of Civil and Environmental Engineering, Norwegian University of Science and \\ Technology (NTNU), Vassbygget, 322, Valgrinda, S. P. Andersens veg 5, 7031 Trondheim, Norway; \\ kaspar.vereide@ntnu.no \\ * Correspondence: bibek.neupane@ntnu.no
}

Citation: Neupane, B.; Vereide, K.; Panthi, K.K. Operation of Norwegian Hydropower Plants and Its Effect on Block Fall Events in Unlined Pressure Tunnels and Shafts. Water 2021, 13, 1567. https://doi.org/10.3390/ w13111567

Academic Editors: Jochen Aberle and Robert Boes

Received: 30 April 2021

Accepted: 30 May 2021

Published: 1 June 2021

Publisher's Note: MDPI stays neutral with regard to jurisdictional claims in published maps and institutional affiliations.

Copyright: (c) 2021 by the authors. Licensee MDPI, Basel, Switzerland. This article is an open access article distributed under the terms and conditions of the Creative Commons Attribution (CC BY) license (https:// creativecommons.org/licenses/by/ $4.0 /)$.

\begin{abstract}
The main objective of this study is to investigate the effect of hydropower plant operation on the long-term stability of unlined pressure tunnels of hydropower plants in Norway. The authors analyzed the past production data of some hydropower plants to find out the number of starts/stops and the frequency and magnitude of load changes. The study demonstrates that an average of 200-400 start/stop events are occurring per turbine per year for the analyzed period, with an increasing trend. Currently, 150-200 large load changes per turbine smaller than $50 \mathrm{MW}$ are occurring every year, and this is expected to increase by $30-45 \%$ between 2025 and 2040 for one of the studied power plants. Most importantly, the monitored pressure transients and pore pressure response in the rock mass during real-time operation at Roskrepp power plant are presented. A new method is proposed to calculate and quantify the hydraulic impact (HI) of pressure transients on rock joints and the effect of duration of shutdown/opening, which is found to be the most dominant parameter affecting the magnitude. The results show that faster shutdown sequences cause unnecessary stress in rock mass surrounding pressure tunnel. The hydraulic impact (HI) can be more than 10 times higher when the shutdown duration is reduced by 50 percent. The study recommends that duration of normal shutdowns/openings in hydropower plants should be slower so that hydraulic impacts on the rock joints are reduced and cyclic hydraulic fatigue is delayed, prolonging the lifetime of unlined pressure tunnels and shafts.
\end{abstract}

Keywords: hydropower; unlined pressure tunnels; hydraulic transients; hydraulic impact; long-term stability; cyclic fatigue; block falls

\section{Introduction}

The world energy market is going through a monumental shift from a fossil-fuel-based system to a renewable energy-based system, following the Paris agreement signed in 2015. According to [1], the share of renewable energy in the power sector would increase from $25 \%$ in 2017 to $85 \%$ by 2050 , mostly through growth in solar and wind power generation. In the Nordic and European power market, the share of solar and wind power is expected to increase from about 20\% to over 55\% between 2018 and 2040 [2].

Technological advances in the field of wind turbines, solar panels, and batteries are increasing the efficiency of these systems and thus reducing their levelized unit cost of energy (LCOE). According to [1], it will be possible to build wind farms at 25 euros/MWh within 10 years. The inclusion of larger amount of wind and solar power causes price volatility due to surplus or deficit of energy at any given time. This also applies for Norway because the share of its regulated production is falling, as the growth in consumption is primarily covered by wind power [3]. This calls for the need to increase flexibility in operation of the existing power production and storage systems. Flexibility is the ability to 
make quick changes in operation at any time such that the balance between production and consumption can always be maintained, with lowest possible cost for carrying out such changes. The need for such flexibility can be both short-term, where changes are needed to balance the system within hours, minutes, and seconds, or long-term, in order to balance the system for days or weeks. There are various solutions that compete to provide flexibility, such as hydropower, hydrogen, and batteries. Among these solutions, regulated hydropower can provide both short- and long-term flexibility.

Norway has almost half of the reservoir capacity in Europe [4], and thus has a great potential for providing the much-needed flexibility for the European power market in the future. Various studies are being conducted to explore this possibility [5-8]. The results indicate that a high proportion of hydropower with large reservoirs has so far resulted in relatively low short-term price volatility in the Nordic region. However, the price volatility is currently increasing, and the operation of the hydropower plants is becoming more dynamic. Operating the existing and new power plants with dynamic operational regime comes with various technical challenges and operational risks. The Norwegian Research Centre for Hydropower Technology (HydroCen) [9] is conducting research in a number of areas to assess such technical difficulties and provide sustainable solutions to meet the future flexibility requirements in Norwegian hydropower system. Its scope of work ranges from long-term stability of structures, electrical and mechanical systems, environmental impacts, and market conditions.

In this article, the authors analyze the production data of some Norwegian power plants to establish some operational trends in order to explore how the operational regimes may influence the long-term stability of unlined hydropower pressure tunnels. Such tunnels constitute the majority of water conveyance system in Norwegian hydropower plants, with a total length of more than $4300 \mathrm{~km}$ and pressurized up to $1047 \mathrm{~m}$ of water pressure $[10,11]$. Since tunnels are unlined, water is in direct contact with the rock mass and the pressure transients resulting from operational changes directly affect the discontinuities in the rock mass, which in the long-term, cause block falls as a result of cyclic fatigue due to frequent pressure pulsations. Further, the authors analyze a two-year long real-time monitoring data [12] consisting of tunnel water pressure and rock mass pore pressure from the unlined headrace tunnel of Roskrepp hydropower plant in Southern Norway. The results are discussed, and the implications of powerplant operation regarding block instabilities in the pressure tunnels are discussed. A recommendation to reconsider the shutdown/opening duration is made based on the findings.

\section{Operation of Hydropower Plants}

\subsection{Data Set}

The data set consists of hourly production data for 10 hydropower plants of different installed capacities ranging from 35 to 960 MW. A total of 21 units ranging from 35 to 320 MW were analyzed, the details of which are shown in Figure 1. The number of starts/stops for all power plants were available for 19 years. However, the amount of production data per hour (MWh) available for each hydropower plant is different. In total, 19 years of data series were available for Roskrepp, Ulset, Brattset, and Driva; 16 years of data were available for Duge; and 6 years of data were available for all the other power plants. Driva, Brattset, and Ulset are located in central Norway in Orkla and Driva rivers and all other power plants are located in Sira and Kvina river valleys in southern Norway, which are connected through a series of reservoirs. The data set for Ulset, Brattset, and Driva was provided by Trønder Energi, and the data set for other power plants was provided by Sira-Kvina Kraftselskap.

In the Norwegian hydropower industry, one of the conditions for issuing a license may be that the hydropower plant is restricted from carrying out sudden and frequent start/stop production, commonly referred to as hydropeaking. This condition specifically applies to hydropower plants with a tailrace directly discharging into a river reach with vulnerable fish species or downstream water use. This requires the hydropower plant to 
be run smoothly and that load changes occur gradually so that sudden changes in the outlet water level are avoided. Evidently, such conditions affect the operational regime of the hydropower plant, which is also of interest in relation to long-term stability of unlined pressure tunnels used to convey the discharge. Out of the hydropower plants that have been used in this analysis, Driva and Brattset have such restrictions against hydropeaking. All the other power plants discharge into downstream reservoirs and have no operational restrictions.

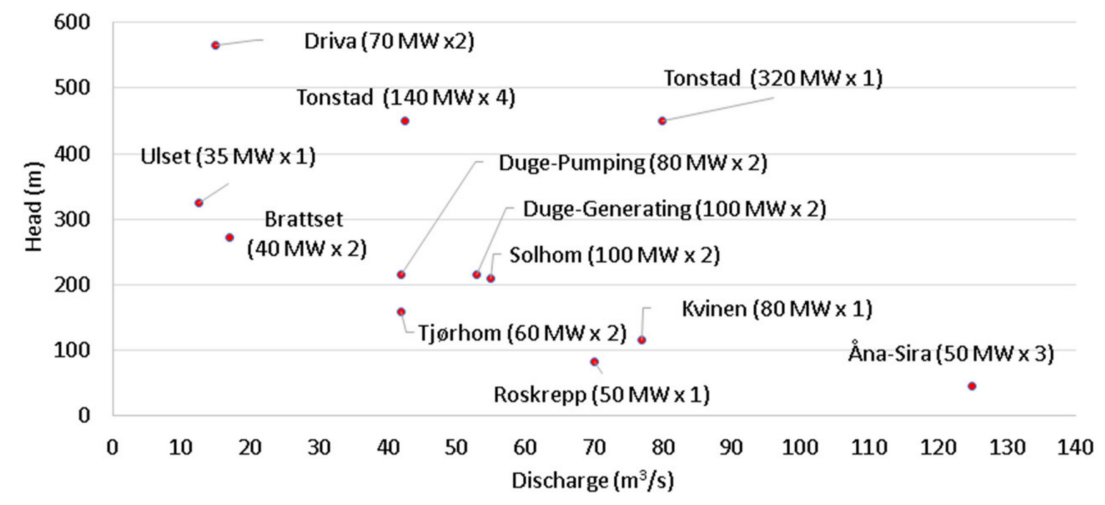

Figure 1. Details of power plant units in the data set.

\subsection{Analysis Method}

The main objective of analysis is to investigate the nature of load changes over the years and to gain knowledge about the magnitude and frequency of such load changes. The finest resolution of production data available is hourly resolution which creates some limitations to do precise calculations of magnitude and frequency of load changes in MW. For example, a production value of $40 \mathrm{MWh}$ could be the result of the power plant being operated at $40 \mathrm{MW}$ for an hour (no load change) or operated at $30 \mathrm{MW}$ and $50 \mathrm{MW}$ for $30 \mathrm{~min}$ each (one load change). Hence, it is assumed that every change in production per hour, larger than the minimum threshold, is a result of a single load-change event. It results in a conservative number of load-change events if more than one event occurs within an hour. However, the results still provide an insight into the nature of load-change events. Further, continuous measurement of water pressure with $10 \mathrm{~Hz}$ frequency at the Roskrepp headrace tunnel for two years (Section 3) shows that multiple load changes within an hour are not frequent; such events occurred seven times during the measurement duration. Hence, the production data were analyzed to count the number of events which matched the load-change types presented in Table 1.

For example, for a $100 \mathrm{MW}$ unit, the maximum possible production per hour is $100 \mathrm{MWh}$. If the change in production between two consecutive hours is higher than $75 \mathrm{MWh}$, it is counted as one event larger than $75 \%$. Depending upon unit capacity, changes in production smaller than a minimum threshold of 2-5 MWh are neglected because small changes may simply occur as a result of change of flow in the brook intake or changing reservoir levels and not necessarily due to turbine operation. The first type, LC1 provides an insight into how frequently the load changes are occurring and its overall trend over the years. The other types provide information about the magnitude of such load changes. Figure 2 illustrates these criteria with some examples. 
Table 1. Load-change types considered for analysis of production data.

\begin{tabular}{|c|c|c|}
\hline Load-Change Type & & Description \\
\hline LC1 & Start/Stop & $\begin{array}{l}\text { Number of starts/stops regardless of the production value when the hydropower } \\
\text { plant is in operation. For example, a load-change event from } 0 \text { to any value higher } \\
\text { than } 0 \text { is counted as one start event, regardless of the load in the second hour, and } \\
\text { vice versa for a stop event. }\end{array}$ \\
\hline \multicolumn{3}{|c|}{$\begin{array}{l}\text { vice versa for a stop event. } \\
\text { Number of load changes between consecutive hours when the magnitude of change is }\end{array}$} \\
\hline $\mathrm{LC} 2$ & $\mathrm{LC}<25 \%$ & smaller than $25 \%$ \\
\hline LC3 & $25 \%<\mathrm{LC}<50 \%$ & between $25 \%$ and $50 \%$, \\
\hline LC4 & $50 \%<\mathrm{LC}<75 \%$ & between $50 \%$ and $75 \%$, \\
\hline LC5 & $\mathrm{LC}>75 \%$ & larger than $75 \%$ \\
\hline
\end{tabular}

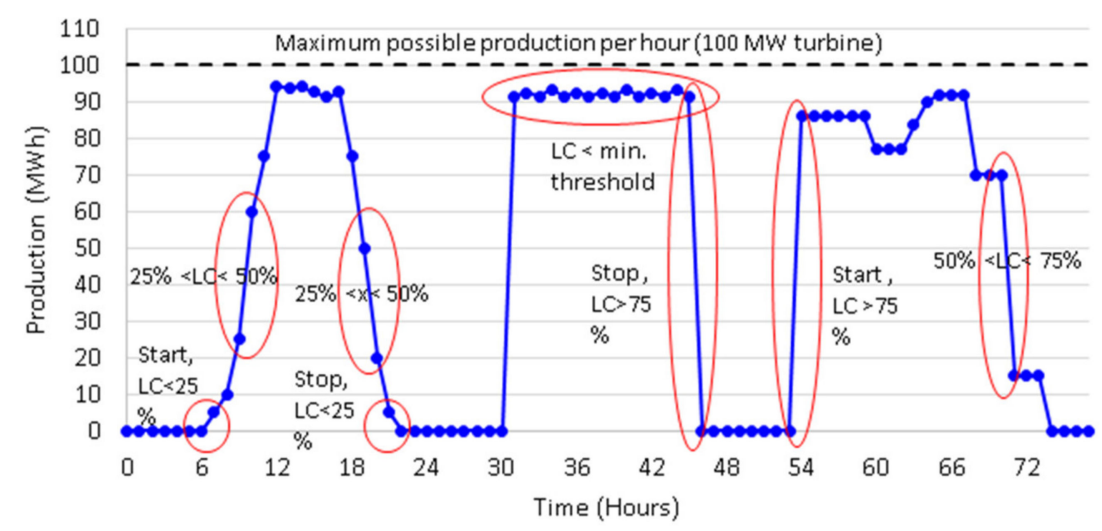

Figure 2. Illustration of the analysis method.

\subsection{Results}

\subsubsection{Starts/Stops}

Figure 3 shows the number of starts/stops for all hydropower plants over the years. Figure $3 c$ shows the results for Tonstad units, which have significantly large capacities as compared to other units in Figure $3 a, b, d$. Figure $3 d$ shows the results for units with operational restrictions, except for Ulset. It can be seen that there are large variations in the start/stop numbers over the years, especially for the hydropower plants without operational restrictions. The main reason for such variations is the power market [13], where production is directly connected to the power prices and financial benefit is the dominant factor. The results also show a general increasing trend in the number of starts/stops after 2009 for all the hydropower plants except Driva, Brattset, and Tonstad. This trend is stronger for smaller hydropower plants. Even with large turbine units, all units of Tonstad still undergo an average of 300-400 starts/stops every year. For power plants with operational restrictions, i.e., Driva and Brattset, the variations are much smaller, and the numbers of total events are also much smaller. This is in agreement with the conditions imposed by environmental regulations as explained before. A similar study carried out by [14] for 256 power plants in Norway with plant capacities up to $15 \mathrm{MW}$ revealed that the number of starts varied from just 1 start to more than 250 starts. The study also concluded that the restrictions on hydropeaking did not really affect the number of starts.

Figure 4 presents statistical values of starts/stops (LC1) events in the power plants. A clear distinction in results is seen between hydropower plants with or without operational restrictions. Both average values and standard deviation are much smaller for hydropower plants with operational restrictions. The lowest number of starts/stops among all power plants is 65 per year per unit for Brattset. All other units experience an average of 200-400 starts/stops every year on average, and there is a large standard deviation in the data set. 


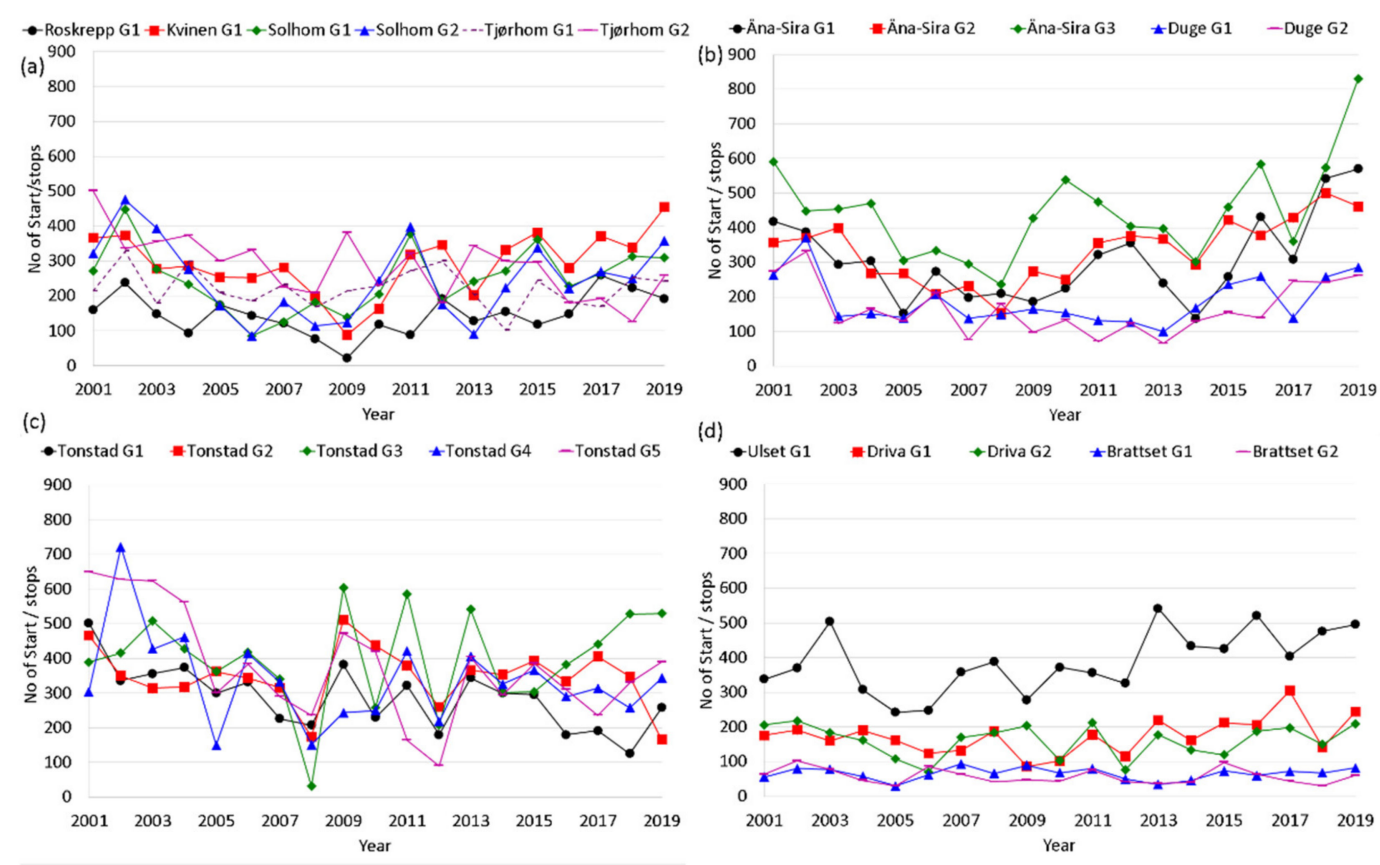

Figure 3. Number of start/stops of various powerplants between 2001 and 2019.

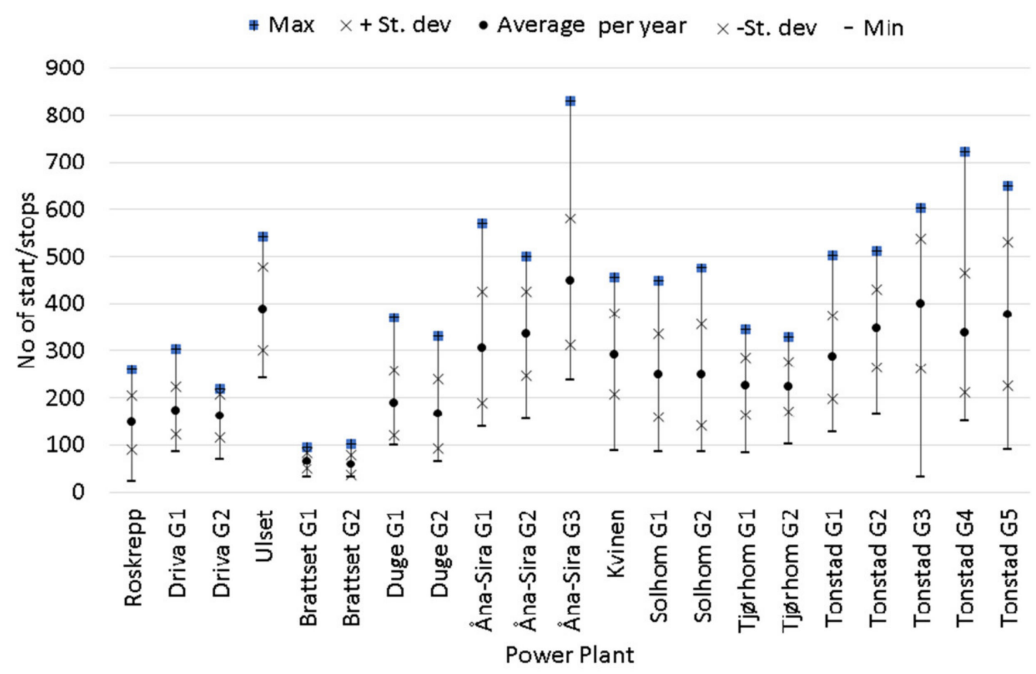

Figure 4. Statistical values of start/stops for various power plants.

Further, it should be noted that for hydropower plants with multiple units, the total number of pressure transients in the waterway caused by starts/stops is the sum of the number of events from all the units. This is because station-wide shutdowns are extremely rare emergency situations. For example, Åna-Sira and Tonstad waterways experience an average of 1100 and 1750 starts/stop events from single-unit operations every year, respectively. This also applies for load changes of various magnitudes, i.e., LC2 to LC5. It is difficult to ascertain whether any station-wide shutdowns had occurred during the period of analysis because of the $1 \mathrm{hr}$ resolution data. For example, in Åna-Sira, one can see that all three units have been shut down from $42 \mathrm{MWh}$ to 0 within an hour, but there are no sufficient data to decide whether all three units were shutdown simultaneously or with some time interval between them.

\subsubsection{Frequency and Magnitude of Load Changes}

Figure 5 presents some statistical values of load-change events that meet the criteria 
presented in Table 1. Results for only the first unit of all power plants are presented for the sake of clarity, because the units have the same capacity (except Tonstad G5) and the results for such units are almost similar.

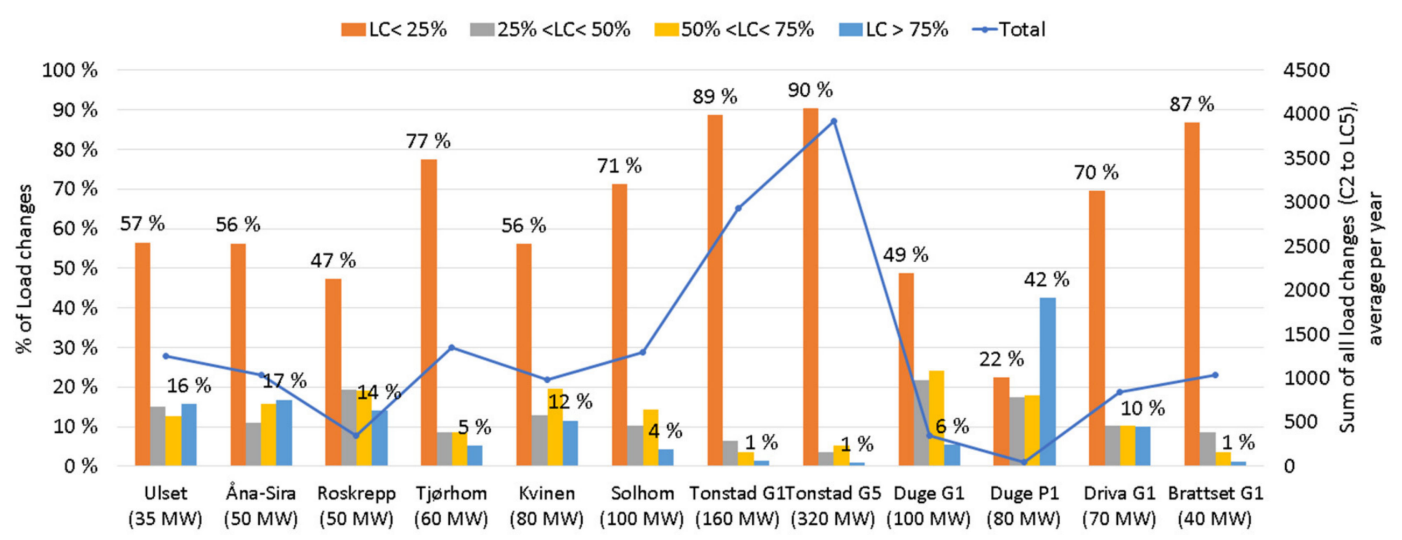

Figure 5. Percentage of load changes of different magnitudes.

For all power plants, the general trend is that there are higher numbers of smaller load changes (LC2) and relatively smaller numbers of larger load changes (LC5). It can be seen that the total number of load changes increases with increasing unit capacity, the highest number being close to 4000 for Tonstad G5. Smaller load changes (LC2) amount from $50 \%$ to $90 \%$ of the total and generally increase with unit capacity. On the contrary, larger load changes (LC5) decrease with the unit capacity. For smaller units such as Ulset and Ana-Sira, the number of LC5 events is more than $15 \%$ of the total, while for large units, it is as low as $5 \%$, with the lowest being $1 \%$. In all cases, the number of medium load changes (LC3 and LC4) are relatively smaller than small load changes (LC1), but they are also in higher proportion for smaller power plants. The results seem logical because for smaller turbines, a relatively smaller change in power price requires a load change which can be relatively larger compared to its capacity. For a larger turbine, a similar change can be handled by making a minor load change. For example, a load change of $30 \mathrm{MW}$ is a large load change for Ulset, medium load change for Roskrepp/Åna-Sira, but a small load change for Tonstad G5. Power plants with operational restrictions, especially Brattset, show a different trend even though they have a small unit capacity; the share of large load changes is significantly smaller ( $1 \%$ of total) than other small units. This also applies for generating mode of Duge because it is primarily operated to serve the purpose of pumping. For Duge pumping mode, the share of large load change is the highest, which is logical because pumping is only possible at full capacity (synchronous generator-motor).

Hence, it can be concluded that power plants with larger units experience more load changes every year but of small magnitudes. Power plants with smaller units, however, experience fewer load changes annually, but the percentage of large load changes is much higher.

\subsubsection{Future Trend in Power Plant Operation}

As discussed in the introduction section, predictions made regarding future energy mix indicate a greater variability in operating condition. With regards to the long-term stability of pressure tunnels and shafts, it is of interest to see how the power prices affect the number of start/stops and frequency of load changes of various magnitudes as described in Table 1. This section presents the results of a production simulation for Roskrepp hydropower plant carried out by Statkraft Energy for different price levels representing the years 2025, 2030, and 2040. Statkraft Energy is also the source of data for the analysis presented in this section. The analysis is carried out using an hourly resolution with hydrological data for a period of 88 years and included all the power plants in the SiraKvina scheme. Four different alternatives were analyzed, including possible upgrading of 
the power plant to pumped storage plant with different capacities as shown in Table 2, and the results are presented in Figure 6.

Table 2. Alternatives for production simulation of Roskrepp hydropower plant.

\begin{tabular}{cc}
\hline Case & Description \\
\hline A0 & Existing situation (50 MW generation only) \\
A1 & Pumped storage plant with 50 MW generation and 50 MW pumping capacity \\
A2 & Pumped storage plant with 50 MW generation and 30 MW pumping capacity \\
A3 & Pumped storage plant with 50 MW generation and 10 MW installed capacity \\
\hline
\end{tabular}

(a) $=\mathrm{LC2}=\mathrm{LC} 3=\mathrm{LC4}=\mathrm{LC5} \rightarrow-$ Total

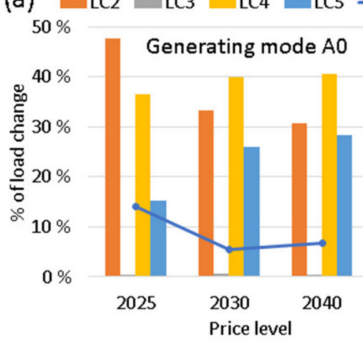

(c) $=\mathrm{LC2}=\mathrm{LC3}=\mathrm{LC4}=\mathrm{LC5} \rightarrow$ Total
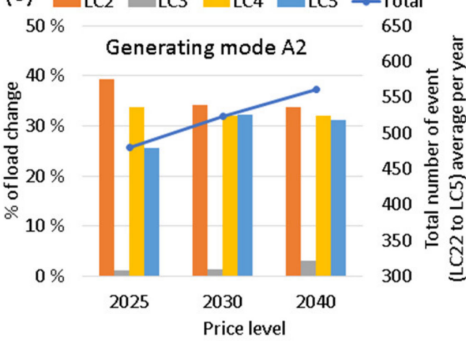

(b)

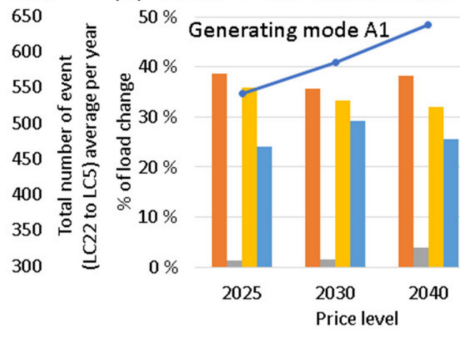

(d)

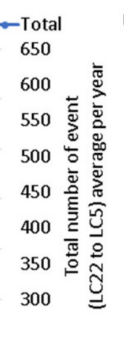

(e)

e) $\quad-\mathrm{A} 0 \rightarrow \mathrm{A} 1 \rightarrow \mathrm{A} 2 \rightarrow \mathrm{A} 3$

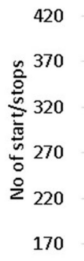

Generating mode
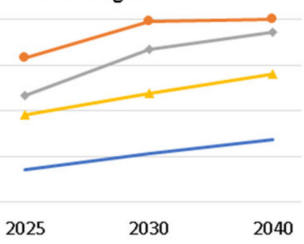

(f)

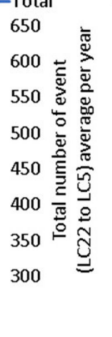

Figure 6. Trend of load changes of different magnitudes with future price levels.

The results show that for all cases of generating mode, the total number of load-change events increases, except for case A0. However, it can be seen that the increase in number of large load changes is the highest between 2025 and 2040 for this case. It can also be seen that the number of large changes (LC5) for all cases increases by $30-45 \%$ between 2025 and 2030 but slightly decreases or remains almost constant between 2030 and 2040 . The number of starts/stops for all cases of generating mode is increasing with time. For all cases of pumping mode, almost all load changes are LC5 since pumping is done with full capacity (synchronous unit). Hence, the number of LC5 events is also equal to the number of starts/stops. It can be seen that the number of LC5 load changes for pumping mode also increases with time, but the rate of increase flattens between 2030 and 2040 . A general conclusion that can be drawn from this analysis is that both the number of load changes and their magnitude are likely to increase significantly over the years. This further emphasizes the fact that tunnels will experience stronger transients with increased frequency in the future.

\section{Tunnel Hydraulics and Hydraulic Impact}

\subsection{Data Set}

The analysis in this section is conducted on the data set acquired from real-time monitoring of unlined headrace tunnel of Roskrepp hydropower plant in southern Norway for a period of two years. The experimental setup is designed by the authors and is described in detail in [12]. The waterway longitudinal section, instrumentation location, and setup are presented in Figure $7 \mathrm{a}-\mathrm{c}$, respectively. Figure $7 d$,e show the instrumented tunnel section and the pressure sensors and datalogger. 

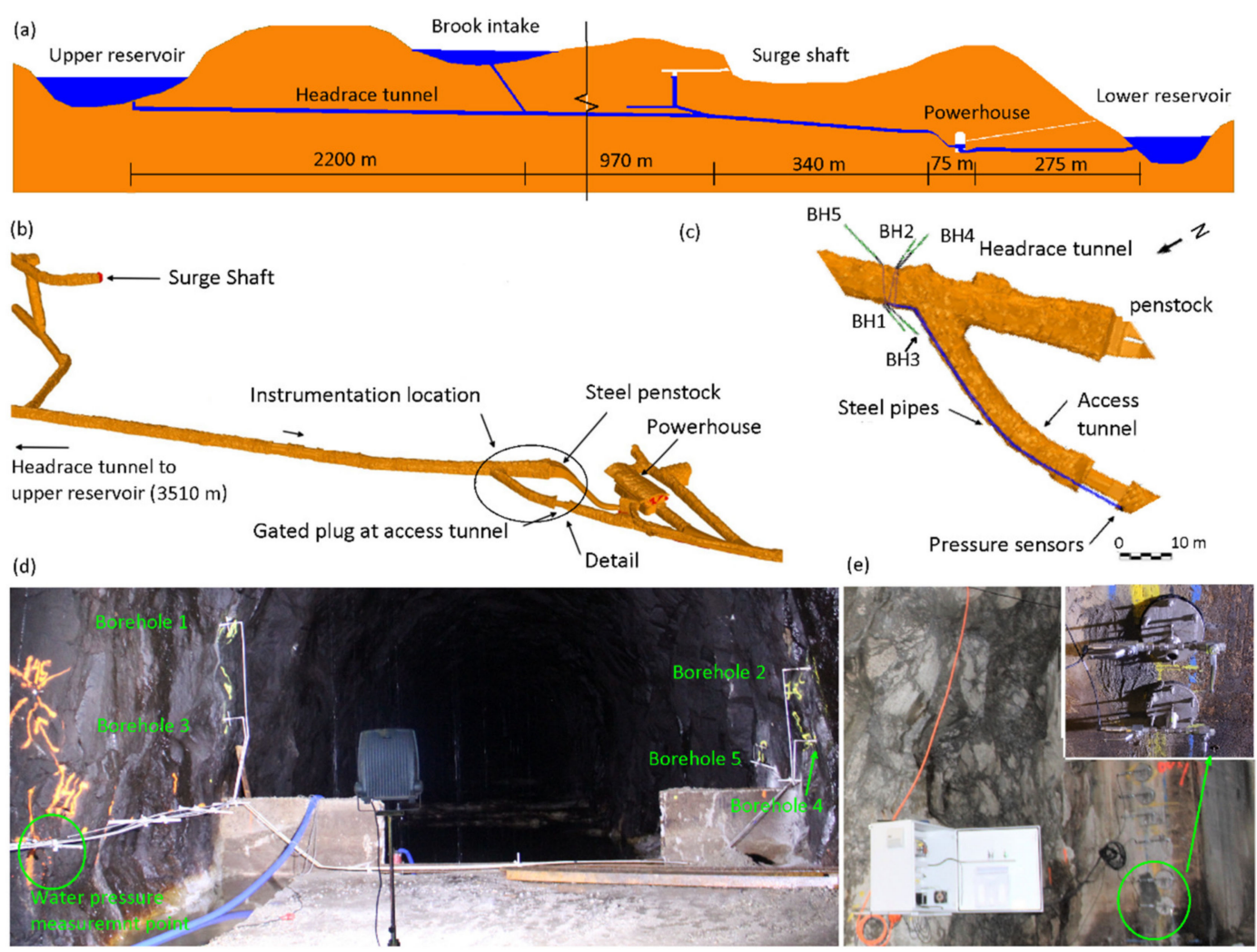

Figure 7. Longitudinal section of Roskrepp waterway (a), instrumentation location (b), and detailed view of the setup with boreholes BH1-BH5 (c), view of the instrumented tunnel section, looking upstream (d), and view of pressure sensors and datalogger in the access tunnel (e).

The rock mass at this location consists of weakly schistose granitic gneiss with three major joint sets. Five boreholes (BH1-BH5) were drilled in the tunnel walls such that they intersect a particular joint set almost perpendicularly. Stainless steel pipes were fixed in the boreholes using packers at different lengths in the borehole and the pipes were taken out of the tunnel to a dry area in the access tunnel, where they were fitted with pressure sensors and datalogger. The section of boreholes ahead of the packers collects water from the rock joints and are connected to the pressure sensors through the steel pipes, thus recording the rock mass pore pressure. Simultaneous readings of the tunnel water pressure are also recorded from a pipe installed at the junction between the headrace tunnel and access tunnel.

\subsection{Shutdown Procedure}

Figure 8 shows a pressure transient in the tunnel and the rock mass pore pressures during a typical shutdown event at Roskrepp hydropower plant. The rock mass pore pressure measured in three boreholes, along with the hydraulic impact during the transient (explained in following section) are shown in the figure. Both water hammer and mass oscillation are recorded by the pressure sensor because the measurement is done at a location between the turbine and the surge shaft.

Shutdowns in hydropower plants can be done in two different ways. An emergency shutdown is the fastest possible closing time for a particular unit and usually only occurs when the unit is stopped by the protection systems or if the unit is disconnected from the power grid during operation. Emergency shutdowns cause strong transients with large pressure amplitudes but are rare. During a normal shutdown, the unit is de-loaded manually in steps by the power plant operator. The purpose in this category of shutdown is to make soft shutdowns in several steps to reduce stresses on the electromechanical components. Both the emergency and normal shutdowns can be divided into two parts: 
(1) the guide vanes closing to reduce the flow through the turbines and (2) the final closing of the slower moving main inlet valve (MIV) to completely stop the flow. In the case of a normal shutdown, the operator decides the number of steps to reduce the power output before the final shutdown signal is given. For example, the operator could run the unit down in $5 \mathrm{MW}$ steps over several minutes or complete the shutdown in a single operation within a few minutes. When the final shutdown signal is given, the guide vanes are fully closed, the unit is disconnected from the grid and starts to decelerate and finally the brakes are activated to bring the unit to a standstill. The MIV normally starts to close after a fixed amount of time after the shutdown signal is given. Usually, this is in between the time when the unit is disconnected from the grid and the time when the unit has fully stopped rotating.

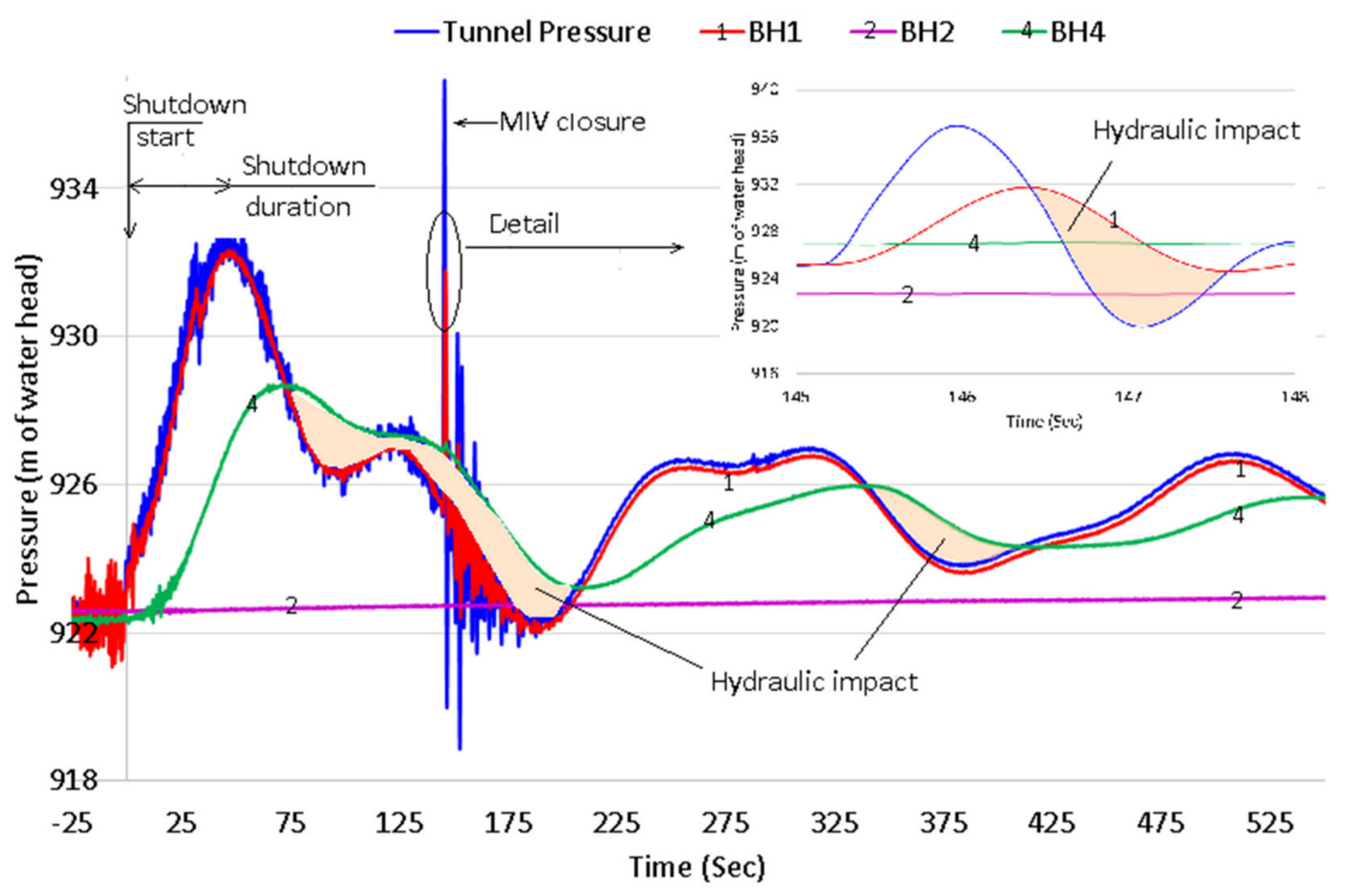

Figure 8. Typical pressure transient with pore pressure responses from boreholes BH1, BH2, and BH4.

It is difficult to ascertain the exact load steps taken for every shutdown event presented here since the data availability is with $1 \mathrm{~h}$ data resolution and this is a manual operation without any fixed standards. Hence, for this analysis, the time between start of shutdown event and the peak mass oscillation amplitude (as shown in Figure 8) is considered to be a relative measure of how fast the shutdown was carried out and is referred to hereafter as "shutdown duration". The measurements show that this parameter significantly affects the pressure readings, which are discussed in the results section.

\subsection{Rock Mass Response and Hydraulic Impact}

Fluid flow in the rock mass mainly occurs through interconnected network of joints and discontinuities since the permeability of intact rocks of igneous and metamorphic origin is negligible. When a pressure transient occurs in an unlined pressure tunnel, the fluid flow and pressure in the rock joints are changed. The change of fluid pressure on the rock joint surfaces causes additional seepage forces to act on these joint surfaces. This is mainly due to water transmission delay or time-lag between pressure peaks in the pressure tunnel and in the joint surfaces of the rock mass. This force can be calculated based on the area bounded between the pressure curves of the tunnel and pressure curves developed in the rock mass when rock mass pore pressure is higher than the tunnel pressure (shaded areas in Figure 8). It can be observed that this situation occurs for some cycles of the 
pressure transient and the number of such cycles depends on the magnitude of time-lag. It gradually decreases as the transient attenuates and both pressures become almost equal or the pressure in the tunnel is higher. This additional force is hereafter named as "hydraulic impact" (HI) and has a unit of MPa.s and is similar to dynamic viscosity or the force acting on the joint surfaces per unit area over time. The hydraulic impact (HI) is a destabilizing force, and the authors regard it to be the main driver for rock block destabilization in the tunnel periphery due to hydraulic transients and may cause rock falls and potentially tunnel collapse.

It can be seen in Figure 8 that the boreholes which intersect the conductive joints in the rock mass, i.e., $\mathrm{BH} 1$ and $\mathrm{BH} 4$, strongly respond to pressure transients, whereas the others are nonresponsive, since they do not have direct hydraulic contact with the conductive joints. $\mathrm{BH} 1$ registers a stronger response to pressure transients, but there is very little time-lag during mass oscillation, resulting in very little to zero hydraulic impact during mass oscillation and significant hydraulic impact during water hammer. For $\mathrm{BH} 4$ on the other hand, a clear time-lag is registered during both mass oscillation and water hammer. However, the amplitude of pore pressure in $\mathrm{BH} 4$ in response to the water hammer is smaller as compared to BH1. This difference in the response is due to different resistance to the flow through joints in the rock mass, which is a function of void geometry of joints and the length of flow path, i.e., joint length between tunnel wall and its intersection points with individual boreholes. The distance between tunnel wall and boreholes (length for flow path) $\mathrm{BH} 1$ and $\mathrm{BH} 4$ are 2.3 and $8 \mathrm{~m}$, respectively.

From a theoretical standpoint, it can be deduced that the hydraulic impact on rock joints is dependent on the magnitude of change of discharge during shutdown and the duration of shutdown event. These two parameters govern the nature of transient pressure pulses which travel inside the rock joints causing additional forces on the joint surfaces. Another important parameter is the static pressure before transient which governs the resistance to flow through joints during transients. The joint hydraulic aperture is influenced by the effective stress across joints. During the operation of a power plant, the effective stress across the joints can vary depending on reservoir levels, which may change the initial hydraulic aperture before transients. Hence, the effect of these three parameters on the hydraulic impact is further analyzed.

\subsection{Method for Calculating Hydraulic Impact}

The total hydraulic impact due to a pressure transient is divided into two parts: due to water hammer and mass oscillation. The hydraulic impact due to water hammer is the sum of the pressure pulses that start when the guide vanes start closing and ends after the MIV has closed. The largest pressure pulse occurs when the MIV is finally closed, and pulses continue to travel between the turbine and surge shaft, until they dissipate after some time (Figure 8). The pressure sensors also register some noise introduced by the vibration of steel pipe caused by the deceleration of the water and turbulence during the shutdown until the final closure of MIV.

\subsubsection{Total Hydraulic Impact}

The total hydraulic impact for each borehole in the rock mass is then calculated as the pressure difference integrated over time between pressure signals at the tunnel and in the boreholes, after removing the noise due to pipe vibration in the pressure signals (the area indicated in Figure 8). A Butterworth filter with low-pass frequency [15] has been used to filter the noise which occurs due to sudden deceleration of water during the guide vane closing phase. A low-pass cutoff frequency of $3 \mathrm{~Hz}$ has been selected. This cutoff frequency is decided using theoretically calculated water-hammer frequency, assuming the wave speed from 800 to $1200 \mathrm{~m} / \mathrm{s}$ and a distance of $87 \mathrm{~m}$ between the turbine and the sensor. The reason for selecting this cutoff frequency is that any pressure wave originating from the turbine which has a frequency higher than this would not be picked up by the sensor because they would not reach the sensor location. Such signals are the result 
of parts of water hammer being reflected by various physical structures and transitions between sensor location and turbine. They would only be recorded if the measurements were done close to the turbine. Hence, the major source of such high-frequency signals in the measurements is mostly pipe vibration. This argument is supported by the fact that signals with frequency higher than $3 \mathrm{~Hz}$ are drastically reduced when the MIV is completely closed. After MIV closure, the net water flow toward the turbines is zero, and hence, there is limited vibration of the pipes. A comparison of HI values due to water hammer computed with and without using the noise filter resulted in a difference of $11 \%$ for $\mathrm{BH} 1$ and $2 \%$ for $\mathrm{BH} 4$.

\subsubsection{Hydraulic Impact Due to Water Hammer and Mass Oscillation}

The water-hammer pulses are superimposed with the mass oscillation, and thus, they need to be isolated in order to calculate their hydraulic impacts separately. Fast Fourier transformation (FFT) of the pressure signal (Figure 9) shows that there are three mass oscillation frequencies corresponding to time periods of 3.4, 1.6, and $1.1 \mathrm{~min}$, moving between reservoir and the surge shaft, between reservoir and brook intake, and between brook intake and surge shaft, respectively. The strongest frequency corresponds to the one that occurs between the reservoir and surge tank, which is also the slowest of the three pulses. The water-hammer pulses were filtered from the pressure signals using the Butterworth filter of cutoff frequency $0.0167 \mathrm{~Hz}$, i.e., time period of $60 \mathrm{~s}$, which is close to the fastest mass oscillation frequency of $0.015 \mathrm{~Hz}$. The area between pressure pulses calculated after using this filter gives the HI value for mass oscillation. The HI value for the water hammer is then calculated by subtracting the mass oscillation $\mathrm{HI}$ from total HI.

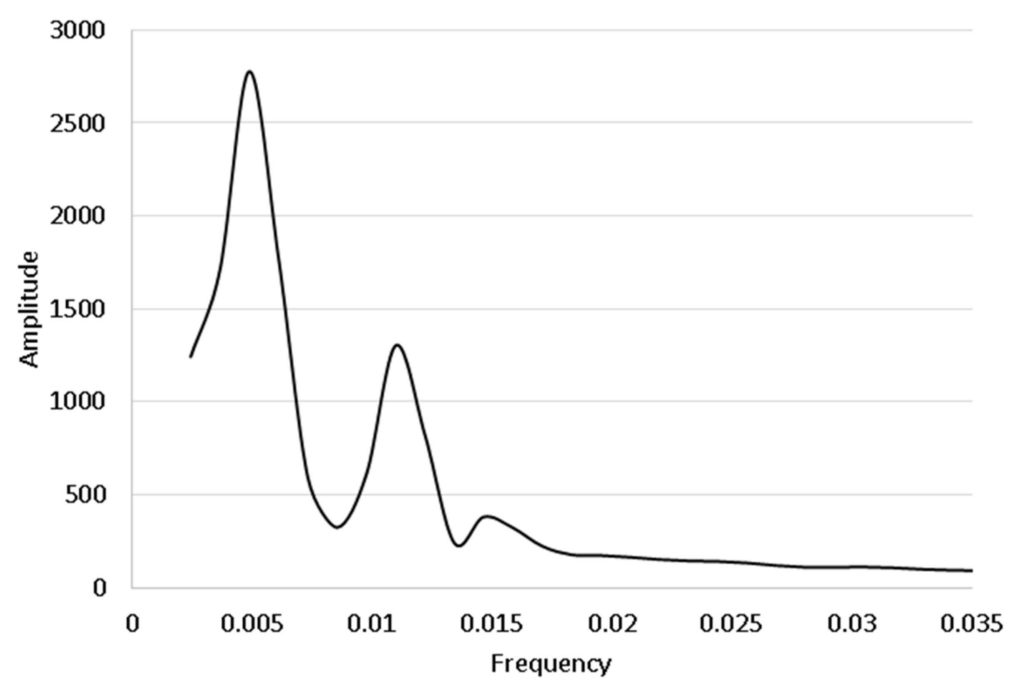

Figure 9. Result of FFT analysis of mass oscillation.

\subsection{Results}

\subsubsection{Effect of Shutdown Duration}

As a result of the differences in the shutdown procedures, normal shutdowns are rarely similar with each other since it is a manual operation and depends on the operator. An example of the effect of such difference is illustrated in Figure 10, which shows pressure signals from two shutdown events with similar durations until MIV closure and similar head loss before transients but producing different pressure signals.

It can be seen that Transient 1 is a result of a gradual de-loading and shutdown, whereas Transient 2 is a faster shutdown, before the MIV closure which occurs almost at similar durations indicated by the largest water-hammer pulses. The mass oscillation amplitude for Transient 2 is larger than Transient 1, and the peak is reached much faster than Transient 1, which is the result of a faster shutdown. Shorter shutdown duration 
(Transient 2) results in a steeper mass oscillation curve which causes a larger time-lag between the pressure peaks in the tunnel and in the rock mass (Figure 10b), since it allows shorter time for the rock mass pore pressure to increase. The time-lag for the first pressure peaks for Transient 1 and Transient 2 are 8.5 and $26 \mathrm{~s}$, respectively. A higher time-lag combined with a larger oscillation magnitude during short shutdown duration results in a larger HI.
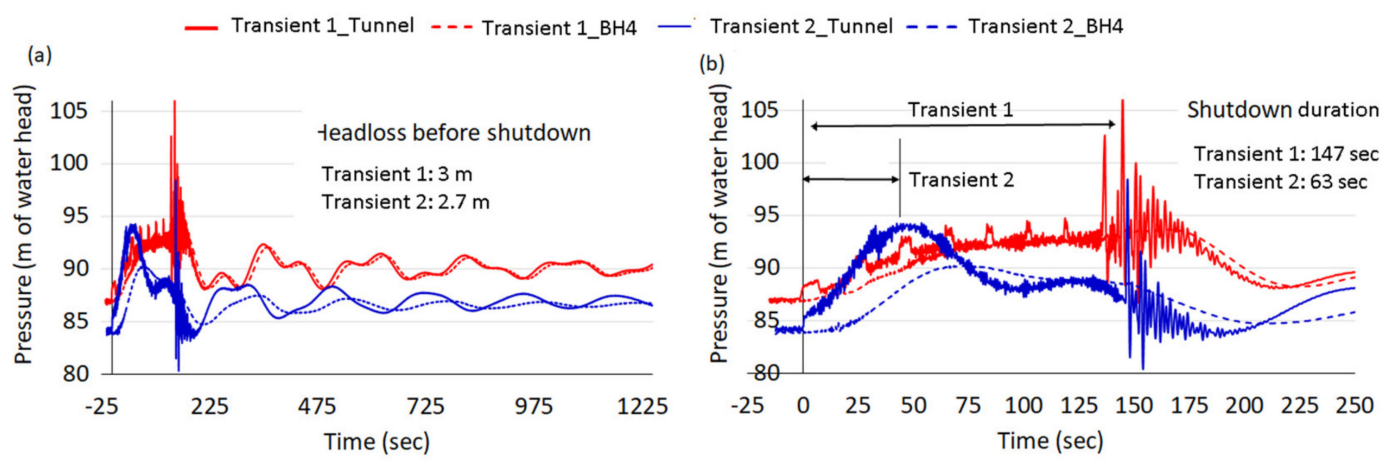

Figure 10. Comparison of pressure signals of two normal shutdowns (a) and enlarged view until $250 \mathrm{sec}$ (b).

Figure 11 shows the hydraulic impact of 161 recorded shutdown events, in relation to their shutdown durations in chronological order. It presents the HI caused by water hammer and mass oscillation for $\mathrm{BH} 4$ along with the shutdown durations and the time-lag of the first mass oscillation pulse for each transient. It can be seen that the time-lag increases significantly with shorter shutdown duration, which consequently increases the HI due to mass oscillation. It is interesting to note the sudden decrease in shutdown duration between event 118 and 119. These two events have occurred within $24 \mathrm{~h}$, and thus the head loss and static pressure before transient for these events are only marginally different. This has caused a sharp increase in time-lag from 6 to $10 \mathrm{~s}$, and in addition, the HI value has increased from 0.8 to 1.9 MPa.s. An even higher increase in time-lag and $\mathrm{HI}$ is seen after event 129. The time-lag and HI after event 129 are larger than $20 \mathrm{~s}$ and $3 \mathrm{MPa} . \mathrm{s}$, respectively.
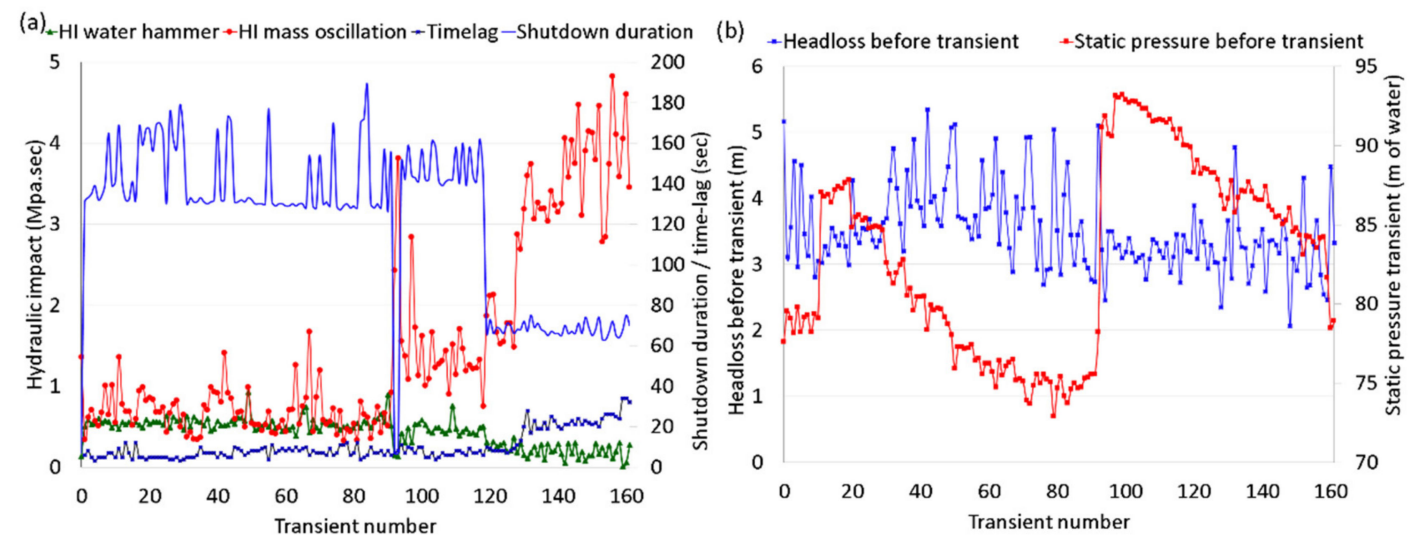

Figure 11. HI for BH4 during various transients in chronological order (a) and corresponding discharge change magnitude and static pressure before transient $(\mathbf{b})$.

The hydraulic impact due to water-hammer increases with longer shutdown duration (Figure 12) because longer shutdown duration allows more water-hammer pulses to occur before the MIV closure. Further, the water-hammer pulses after MIV closure also have some time-lag which contributes to additional HI. It can be seen that mass oscillation causes almost no hydraulic impact for BH1.This is because the time period of mass oscillation is much slower, and thus, it allows pore pressure build-up in the borehole almost with the same rate as the pressure pulse, thus preventing any time-tag. This shows that the rock 
mass can respond differently for varying time periods even with same joint conditions or flow resistance. The effect of the time period on HI and joint deformation has been analyzed in detail in [16] using numerical simulation.
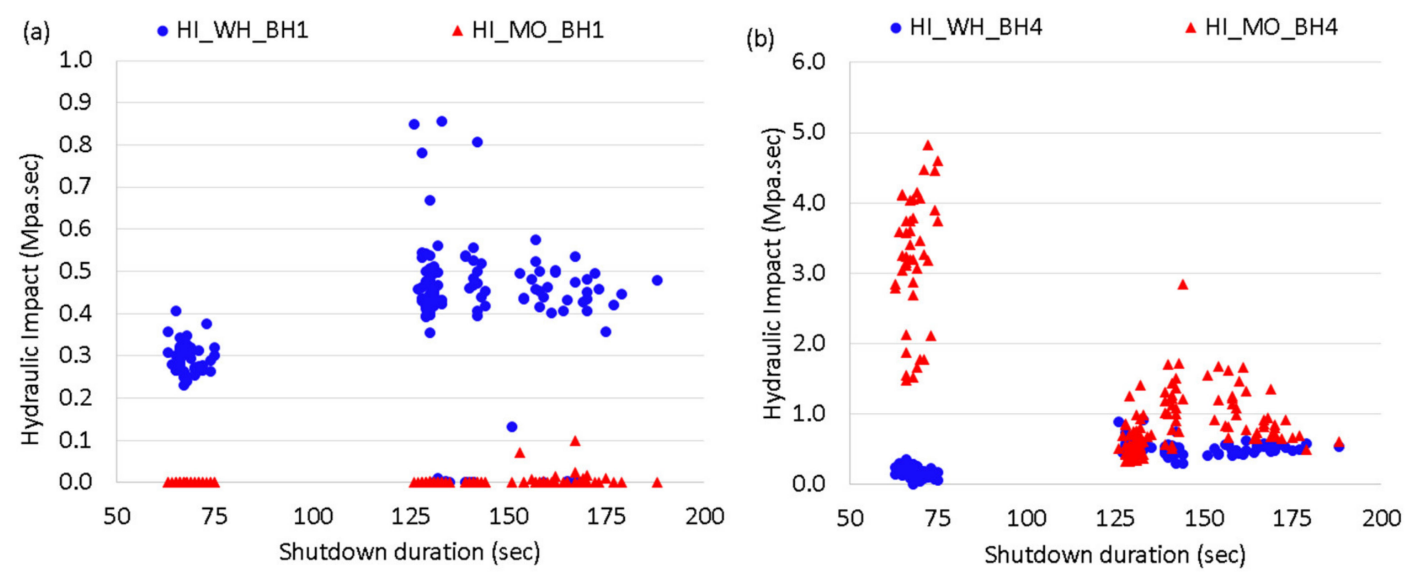

Figure 12. Effect of shutdown duration on hydraulic impact (a) for $\mathrm{BH} 1$ and for $\mathrm{BH} 4$ (b).

For $\mathrm{BH} 4, \mathrm{HI}$ caused by water hammer is in a similar range as for $\mathrm{BH} 1$. The HI caused by mass oscillation is significant for $\mathrm{BH} 4$ because the flow resistance is higher, as the length of flow path is larger than for $\mathrm{BH} 1$ and thus causes significant time-lag. It can be seen that faster shutdowns cause larger HI, and it is more than 10 times higher when the shutdown duration decreases from 130 to $65 \mathrm{~s}$. Further, it is interesting to note the contribution of water hammer in the total hydraulic impact during pressure transients. For longer shutdown durations ( 125 to $200 \mathrm{~s}$ ), water hammer contributes $40 \%$ of the total $\mathrm{HI}$ on average, the minimum and maximum values being $3 \%$ and $65 \%$, respectively. However, for faster shutdowns (below $75 \mathrm{~s}$ ) the average, minimum, and maximum values are $7 \%$, $1 \%$, and $20 \%$, respectively.

\subsubsection{Effect of the Discharge Change Magnitude}

The head loss between the reservoir and the measurement location before the shutdown event is a measure of the magnitude of discharge change in the waterway. Larger head loss means larger change in discharge and large load change during a shutdown event. Calculation of the discharge during each transient is not attempted because the discharge added in the tunnel from the unregulated brook intake introduces uncertainties in the calculation. In general, a shutdown from a larger discharge should result in a larger mass oscillation. However, a distinct relation between the discharge change magnitude and $\mathrm{HI}$ due to mass oscillation was not observed as was the case for shutdown duration. Figure 13 shows two different clusters of HI values for mass oscillation which are strongly influenced by shutdown duration.

Most of the HI values above 2 MPa.s (Figure 13a) correspond to shutdown durations smaller than $75 \mathrm{~s}$ and show a somewhat increasing trend with larger head loss before a transient. The majority of values below $2 \mathrm{MPa}$.s correspond to shutdown durations longer than $125 \mathrm{~s}$ and tend to show a decreasing trend with increase in head loss. However, a shutdown from a larger discharge should result in a larger mass oscillation and hence larger HI. This opposite trend can be explained by the fact that there is a greater variation in shutdown duration larger than $125 \mathrm{~s}$ (Figure 13b). Hence, it is concluded that shutdown duration is more dominant parameter as compared to the discharge change magnitude. This is because the gradient of pressure change is more important than magnitude, as seen from the measurements. 

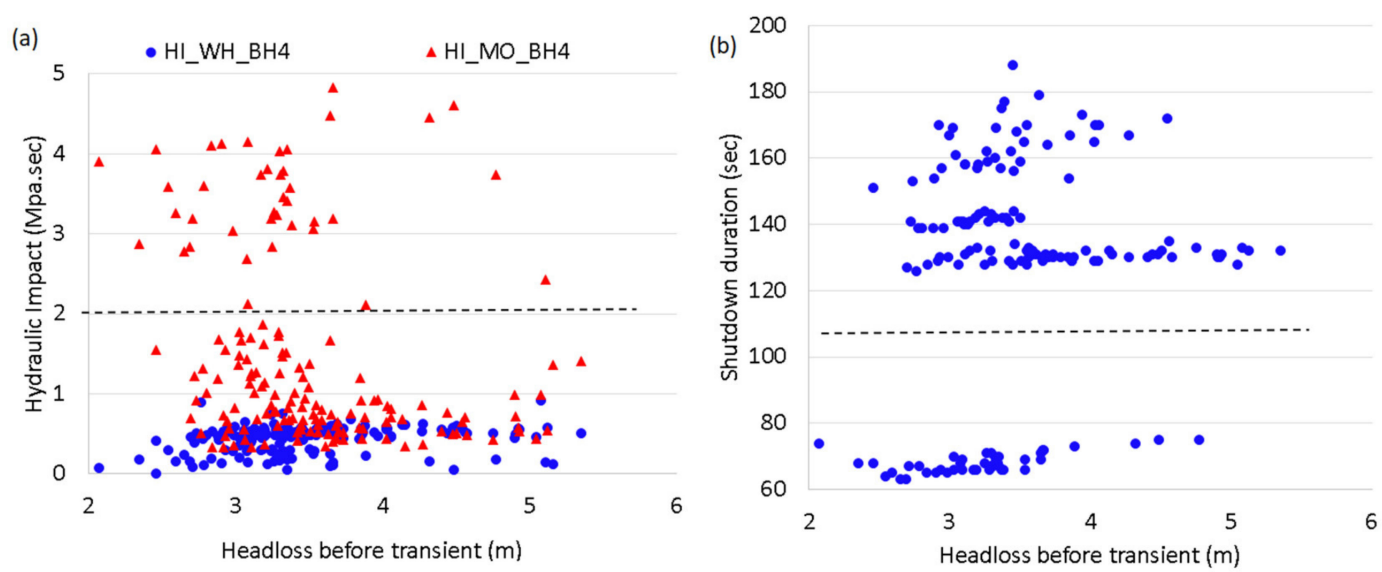

Figure 13. Hydraulic impact in relation to the magnitude of discharge change (a) and magnitude of discharge change vs. shutdown duration $(\mathbf{b})$.

\subsubsection{Effect of Static Pressure before Transient}

The static pressure before transient can have some influence in the shape of the mass oscillation curves because of two reasons: (1) it decides from which water level in the surge tank and brook intake that the oscillation starts, and (2) different static heads may mean different water levels in the reservoir. This could affect the HI due to mass oscillation to some extent. However, Figure 14 shows that the $\mathrm{HI}$ values are unaffected by the increase in static pressure. The largest values inside the oval are from the events with the shortest shutdown duration (event 118 to 161).

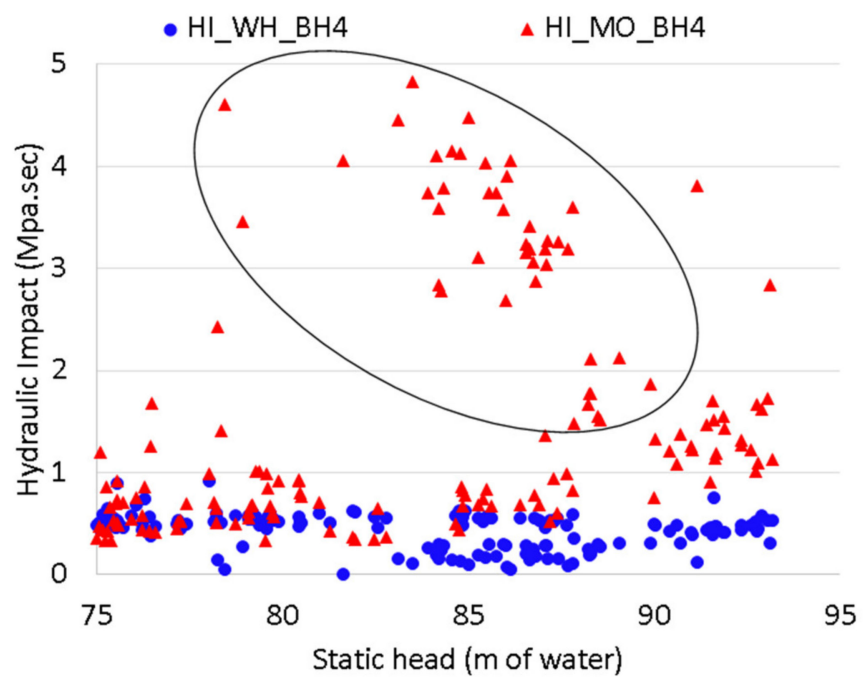

Figure 14. Effect of static head before transient on hydraulic impact.

The explanation to why the result is almost unaffected by the static pressure is most likely because effective stresses are much larger as compared to the change in static head and static pressure and are not large enough to cause significant changes in the joint aperture. Further, the high stiffness of the joint surface for hard rocks can prevent noticeable changes in the joint aperture.

\subsubsection{Effect of Tunnel Dewatering}

As shown in Figure 15a, the tunnel was dewatered after event 126 in spring, and then the refilling was done after two months during summer and event 127 occurred in autumn. According to [17], the controlled tunnel filling or dewatering in Norwegian unlined pressure tunnels and shafts is generally carried out at a rate of $15 \mathrm{~m}$ head increase/decrease per 
hour with a stop for minimum $2 \mathrm{~h}$ per $150 \mathrm{~m}$ head change and maximum head of $300 \mathrm{~m}$ per day. This is done in order to reduce excess hydraulic impact on rock mass around tunnel during filling and dewatering. The static head at the measurement location in the Roskrepp tunnel before dewatering was $80 \mathrm{~m}$, and the dewatering was conducted in two stages within a duration of $7 \mathrm{~h}$. The pore pressure sensors connected to $\mathrm{BH} 1$ and $\mathrm{BH} 4$ record $\mathrm{HI}$ values of 3 and $20 \mathrm{MPa}$.s, respectively, over the dewatering duration.
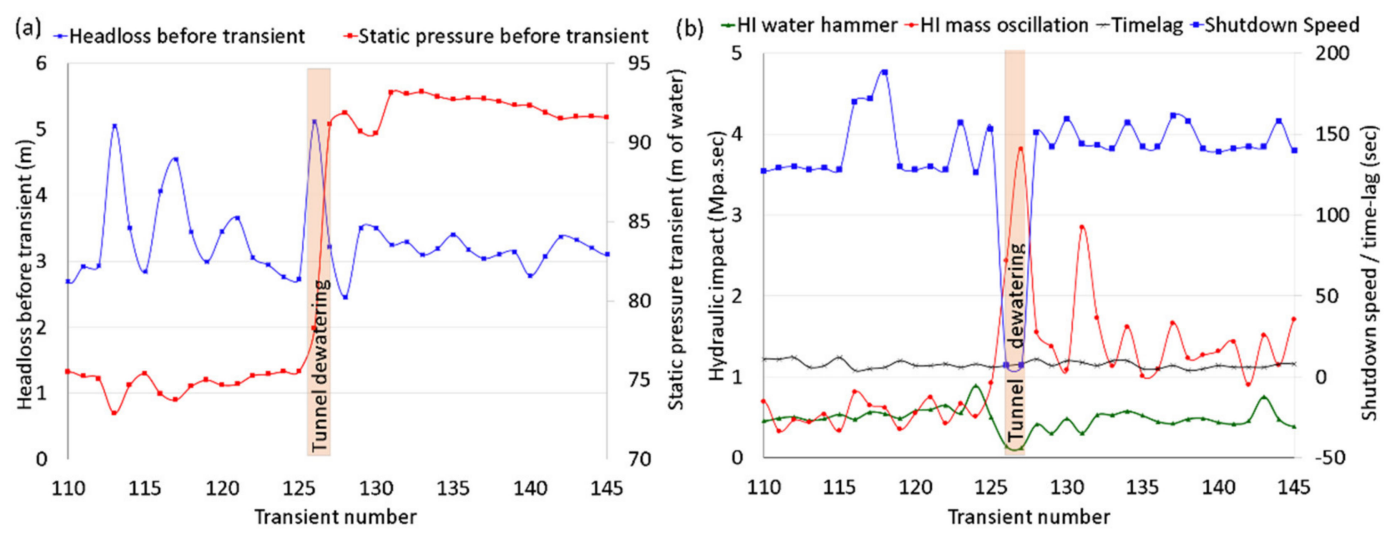

Figure 15. Discharge change magnitude and static pressure before transient for events 110-145 in chronological order (a) and corresponding $\mathrm{HI}$ for various transients $(\mathbf{b})$.

It is observed that normal shutdowns after event 127 show increased $H I$ values which are greater than 1.5 MPa.s, whereas the values before this event were in the range of 0.5-1 MPa.s. (Figure 15b). The static head before transient has significantly increased because event 127 occurred in autumn, after the reservoir had been filled by snowmelt during the spring and summer. However, as discussed in the previous section, this has no significant influence on the HI. Hence, it shows that dewatering is the reason for increase in $\mathrm{HI}$ values after event 127 . Sudden increase in hydraulic impact (HI) after dewatering suggests that it has caused irreversible changes in the joint void geometry possibly caused by shear displacement, increasing the joint permeability, and thus allowing more flow into the joint during transients. This is a reasonable explanation because tunnel dewatering is known to cause macroscopic joint displacements and block falls, because the draining of rock joints takes time and rock mass pore pressure exceeds the tunnel pressure during such events. This occurs until the rock mass is fully drained and pressures are equalized.

Further, it should be noted the events 126 and 127 are emergency shutdowns with shutdown durations of $7 \mathrm{~s}$, which caused significantly high hydraulic impacts (2.5 and 3.8 MPa.s) as compared to previous events. A similar phenomenon was also reported by [18] in the air cushion surge chamber of Osa power plant where significant increase in air loss was experienced after a few turbine rejections with pressure rise as high as $20 \%$ of static pressure Hence, the difference in $\mathrm{HI}$ values could thus be linked to both dewatering as well as contribution from the emergency shutdowns. Nevertheless, more measurements are needed to investigate whether emergency shutdowns alone can cause a noticeable change in behavior.

\section{Discussion}

The underlying axiom of block theory is that the failure of an excavation begins at the boundary with the movement of a block into the excavated space [19]. This implies that the orientation of joints should be conducive to create a wedge in order to cause a block fall. Further, removal of key blocks could result in extended fallouts. The existing block theory is still applicable for assessing the block falls due to tunnel operation, except for the fact that additional destabilizing forces are created during hydropower plant operation. This is not a one-time event but a cumulative effect of many small events, referred to as cyclic fatigue, which occurs over the course of hydropower plant operation. During 
tunnel excavation, potentially unstable wedges are identified, and adequate support is provided. However, relatively stable and unsupported blocks during construction may be destabilized as a result of weakened joints due to long-term fatigue over the years of hydropower plant operation. In some occasion, the potential rock blocks are not detected during construction. More importantly, some blocks may be held together by an intact rock bridge posing no threat of block falls during construction. Such intact rock bridges can gradually weaken due to the cumulative effect of $\mathrm{HI}$ and eventual rupture causing block falls. Similar findings have been highlighted by Preisig et al. [20] where the rupture of intact rock bridges due to seasonal pore pressure changes are attributed as the cause of progressive failure and fatigue in deep-seated landslides.

Figure 16 shows an example of a block fall witnessed in the TBM section of the $4.5 \mathrm{~m}$ diameter unlined headrace tunnel of Ulset power plant, which has been in operation since 1985. Unlined tunnels are generally dewatered for inspection after one year of operation to investigate if there are large block falls which could pose major stability issues in the future. The first inspection of this tunnel was conducted in 1986 after one year of operation, which revealed no major instabilities but showed some minor block falls [21]. For unlined pressure tunnels, minor block falls are expected during the first inspection because the rock mass is subjected to a new ground water regime and reduced effective stresses after tunnel filling. The washing of joint infilling material also reduces joint stiffness, which further contributes to block falls. The situation stabilizes after a new equilibrium is reached. The second inspection report carried out in 1992 [22,23] also does not show any serious instability issues. The last inspection was conducted by the first and third author of this article in 2017. During this inspection, several block falls similar to the one shown in Figure 16 were observed along the whole TBM tunnel length. From the Roskrepp measurements, it is now evident that additional load or hydraulic impact occurs during load changes. Hence, it is postulated herein that such block falls are the result of rock mass fatigue caused by cumulative HI due to transient events with load changes over the years. It is noted that the operational regime of Norwegian hydropower plants has changed after the deregulation of power market in 1991 [13]. This is most likely a contributing factor for the observed block falls because the deregulation has resulted in more start/stops and load-change events.

The results presented in previous sections clearly indicate that additional load on rock joints or $\mathrm{HI}$ due to hydropower plant operation depends on the shutdown duration and the magnitude of load changes. With the increase in intermittent energy in the future power system, it is very likely that both these parameters will be affected. Results from the analysis of production data show that both the number of starts/stops and frequency and magnitude of load changes will increase in the future. This means that the tunnels will experience stronger transients with increased frequency, causing more transient cycles with higher $\mathrm{HI}$ and accelerated fatigue.

The analyses show that hydropower plants with smaller units experience smaller number of load changes every year, but the proportion of large load changes relative to their plant capacities are much higher. This means that their waterways experience more transients with larger amplitudes relative to the static pressure. The minimum design factor of safety against mass oscillations in unlined pressure tunnels is 1.3 [24], meaning the normal stress acting against a critical joint must be at least $1.3 \mathrm{MPa}$ if the design tunnel static pressure is $1 \mathrm{MPa}$. A larger load change causes bigger mass oscillation amplitudes which are closer to critical normal stress (or reduced factor of safety). Frequent events with such oscillation pressures close to critical normal stress contribute to accelerating the cyclic fatigue, especially if the transients occur when the tunnel static pressure is close to design static pressure. On the other hand, small transients even though in larger numbers may not necessarily have a higher impact on the rock mass. This could suggest that the rock mass around the tunnel in smaller hydropower plants may experience fatigue at a faster rate, assuming similar rock mass and effective stress conditions. However, it is difficult to ascertain in absolute terms whether a relatively strong transient in hydropower plants with low static head is more damaging than relatively weaker transient in hydropower 
plant with high static head. It is highlighted that the $\mathrm{HI}$ is dependent on the resistance to flow through joints, which is a function of void geometry of joints in the rock mass and the length of flow path, i.e., length between tunnel wall and any particular point in the rock joint inside the tunnel wall. Hence, the HI values presented in the results are specific for the length of joint between tunnel wall and $\mathrm{BH} 1 / \mathrm{BH} 4$. The variation of $\mathrm{HI}$ along joint length with different rock-mechanical properties such as joint stiffness, friction angle and dilation, and effective stresses is studied in detail by [16] using numerical simulation.

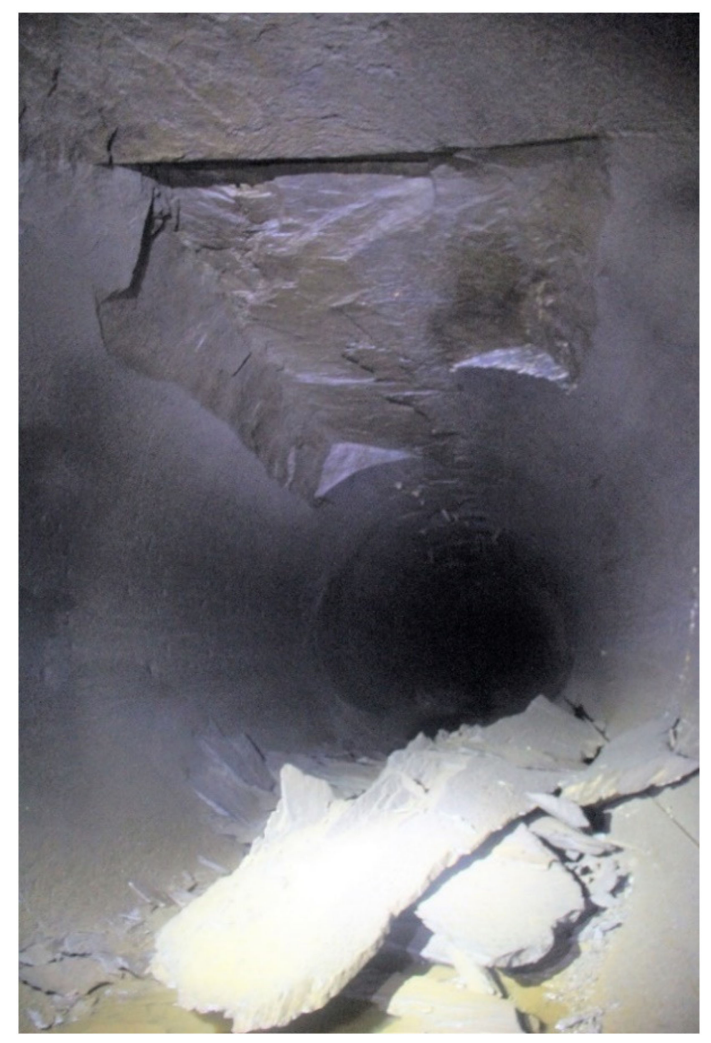

Figure 16. Example of block fall witnessed in Ulset headrace tunnel in 2017.

The analysis shows that shutdown duration is the most dominant parameter affecting hydraulic impact (HI) on rock joints. The results presented in this work are only from shutdown or reduction of load in the hydropower plant. Pressure transients also occur in the system when increasing load or opening the turbine valves, which also cause significant hydraulic impact. It can be inferred that similar to shutdown duration, the duration of opening has a significant impact since it also affects how the mass oscillation pressure develops during the transient.

A larger share of intermittent energy demands for increased flexibility in operation, which may mean that power plants need to change load faster, hence affecting the shutdown duration. However, it is uncertain to what extent the shutdown duration is affected owing to higher flexibility needs. As seen from the measurement and analysis, the current trend of shutdown duration as seen in Roskrepp is still contributing to accelerate the rock mass fatigue, which is explained below.

Based on the results, it would be logical that for larger load changes, both shutdown and opening should be carried out slowly to avoid stronger transients. However, it is dependent on the individual power plant operators due to lack of standard procedure for normal load-change operations. In Figure 13b, we can see that the shutdown duration is irrespective of head loss before the transient and three distinct clusters of shutdown durations are seen for similar head loss values. As seen in the results, faster shutdown causes significantly larger HI, which could be reduced by a slower shutdown. For example, 
for head loss of $3 \mathrm{~m}$, the shutdown durations vary from 170 to $65 \mathrm{~s}$, and the HI due to mass oscillation are 3-9 times higher (Figure 12). This could be avoided by having a slower normal shutdown. The idea is to carry out normal shutdowns/openings based on the magnitude of load changes such that larger load changes take longer shutdown/opening durations. These durations should be long enough for the rock mass pore pressure to closely follow the change in pressure in the tunnel during a transient. The optimum shutdown duration must be decided individually for each hydropower plant since the hydropower plants are unique in terms of parameters such as rock joint conditions in the tunnel contour, design head and discharge, length of the waterway, and number of brook intakes, contributing to different nature of the mass oscillations. As seen from the Roskrepp measurements, shutdown durations larger than $200 \mathrm{~s}$ seem to give the lowest possible impact with respect to shutdown from full load and is the recommended shutdown duration from full load for this power plant to reduce the hydraulic impact.

For hydropower plants to be constructed in the future or upgraded, a larger surge tank can be designed to reduce the pressure rise and also the time between start of shutdown and maximum mass oscillation amplitude, i.e., the shutdown duration becomes longer. In the case of pre-existing hydropower plants, slower operation of the units may be the most reasonable solution to reduce the hydraulic impact on rock mass around unlined pressure tunnels.

Slower shutdowns/openings cause lower hydraulic impact on the rock mass, which would help slow down the fatigue process. It is envisaged that such slow shutdowns/openings could be done in two different ways: (1) by standardizing a slow manual loading/deloading of the units or (2) by using a slow preprogrammed and automated governor operation routine. Such measures may help to reduce the number of block falls and prolong the serviceable lifetime of unlined pressure tunnels and shafts.

Prediction of block falls due to transient events is a challenging issue because of the lack of a governing equation that defines the process of cyclic fatigue due to external (hydraulic) and internal (gravitational, friction and shear) forces that cause the failure of rock joints and intact rock bridges. Large variation in the hydromechanical properties of rock joints and in situ rock stresses add challenges in quantifying the hydraulic impact and the eventual fatigue. Further, the cumulative effect of $\mathrm{HI}$ is difficult to quantify in real cases since no monitoring systems are installed to record the pore pressure and long-term deformation in the rock mass. However, back analysis of particular block fall cases may be carried out using advanced numerical modelling with specific input parameters such as joint orientations, hydromechanical properties, in situ stress conditions, and pressure oscillations, which would help to gain more knowledge to address the aforementioned challenges.

\section{Conclusions}

The production data of some Norwegian hydropower plants shows that there is a large variation of start/stop events for each hydropower plant every year and also between different hydropower plants. The hydropower plants without operational restrictions have average annual start/stop events between 200 and 400 per unit, with a standard deviation up to 150. It is also seen that the number of start/stop events are in increasing order after the year 2009, and this increasing trend is significant for smaller hydropower plants. Further, the study of the magnitude of load changes in these hydropower plants suggests that there are higher numbers of smaller load changes (smaller than $25 \%$ of full capacity per hour) and smaller numbers of larger load changes (larger than $75 \%$ of full capacity per hour). More importantly, larger load changes are in higher proportion (more than $15 \%$ of total load-change events) for smaller power plants as compared to larger hydropower plants. This amounts to about 150-200 large load changes per turbine with installed capacity smaller than $50 \mathrm{MW}$. The production forecast for Roskrepp hydropower plant suggests that start/stop events and large load changes will increase by 30-45\% between 2025 and 2040. From these observations, the authors conclude that dynamic operation of hydropower 
plants shows an increasing trend which can lead to larger destabilizing forces in the rock joints and accelerated fatigue of the rock mass in the future.

The monitored pressure transients and the pore pressure response in the rock mass during real-time operation at Roskrepp power plant have been used to develop a new method to quantify the effect of hydraulic transients on rock joints, referred to as the hydraulic impact (HI). The hydraulic impact is a destabilizing force that is regarded to be the main driver for instability, rock blocks fall, and potential tunnel collapses caused by hydraulic transients. The authors conclude that the duration of shutdown during a load reduction event is the most dominant parameter regarding the hydraulic impact, followed by the magnitude of load change. The faster the shutdown event, the higher the hydraulic impact, and it is more than 10 times higher when the shutdown duration is halved (i.e., from 130 to $65 \mathrm{~s}$ ). The measurements show that tunnel dewatering has also caused significant increase in hydraulic impact, indicating irreversible changes in the joint void geometry and increase in the joint permeability, which can contribute to block falls over long-term operation.

It is observed that there is a large variation in shutdown duration, even for similar magnitude of load changes, ranging from $60 \mathrm{~s}$ to $200 \mathrm{~s}$, because there is no standard procedure for shutdown duration and is entirely up to the operators to decide. Based on the results in this work, the authors recommend that durations of normal shutdowns/ openings should be longer than current practice so that changes in pore pressure in the rock mass are more gradual. Normal shutdowns/openings should be carried out based on the magnitude of load changes such that larger load changes take longer shutdown/opening durations. Slower shutdowns/openings cause a slower pressure increase in tunnels and shafts and, thus, a lower hydraulic impact on the rock mass, which would help slow down the cyclic fatigue process.

Author Contributions: Conceptualization, B.N., K.V. and K.K.P.; methodology, B.N.; formal analysis, B.N.; data investigation, B.N.; resources, K.V. and K.K.P.; data curation, B.N. and K.V; writingoriginal draft preparation, B.N.; writing - review and editing, K.V. and K.K.P.; visualization, B.N.; supervision, K.K.P. and K.V.; project administration, K.K.P.; funding acquisition, K.K.P. and K.V.; All authors have read and agreed to the published version of the manuscript.

Funding: This research is conducted and financed as a part of the Norwegian Research Centre for Hydropower Technology (HydroCen).

Institutional Review Board Statement: Not Applicable.

Informed Consent Statement: Not Applicable.

Data Availability Statement: Data cannot be shared due to confidentiality.

Acknowledgments: The authors grateful to Sira-Kvina kraftselskap, TrønderEnergi for providing the power plant production data. The authors are also thankful to Statkraft Energy for providing the production prognosis for future operation of the Roskrepp power plant. The authors express their gratitude to Sira-Kvina kraftselskap for allowing the access and instrumentation at Roskrepp power plant and funding the site installation, and Torkjell Breivik, Senior Engineer at the Department of Geoscience of Petroleum for his work in LabVIEW for the data acquisition and visual interface.

Conflicts of Interest: The authors declare no conflict of interest. The funders had no role in the design of the study; in the collection, analyses, or interpretation of data; in the writing of the manuscript, or in the decision to publish the results.

\section{References}

1. International Renewable Energy agency (IRENA). Global energy transformation. A roadmap to 2050. 2018. Available online: https:/ / irena.org/publications/2018/Apr/Global-Energy-Transition-A-Roadmap-to-2050 (accessed on 6 April 2021).

2. Statnett. Long-Term Market Analysis. The Nordic countries and Europe 2018-2040. (In Norwegian). Available online: https: / / www.statnett.no/globalassets/for-aktorer-i-kraftsystemet/planer-og-analyser/langsiktig-markedsanalyse-nordenog-europa-2018-40.pdf (accessed on 29 March 2021). 
3. Energy Facts Norway. Available online: https://energifaktanorge.no/en/norsk-energiforsyning/kraftproduksjon/\#wind-power (accessed on 6 April 2021).

4. Statkraft. Available online: https://www.statkraft.com/what-we-do/hydropower/ (accessed on 29 March 2021).

5. Pitorac, L.; Vereide, K.; Lia, L. Technical Review of Existing Norwegian Pumped Storage Plants. Energies 2020, 13, 4918. [CrossRef]

6. Statkraft. Global Energy Trends. Statkraft's Low Emissions Scenario 2019. Available online: https://www.statkraft.com/ globalassets /1-statkraft-public/lavutslipsscenario/low-emissions-scenario-2019.pdf (accessed on 29 March 2021).

7. Statnett. Flexibility in the Norwegian Power Market 2018-2040. 2018. (In Norwegian). Available online: https:/ / www.statnett. no/globalassets/for-aktorer-i-kraftsystemet/planer-og-analyser/2018-Fleksibilitet-i-det-nordiske-kraftmarkedet-2018-2040 (accessed on 29 March 2021).

8. Graabak, I.; Jaehnert, S.; Korpås, M.; Mo, B. Norway as a Battery for the Future European Power System-Impacts on the Hydropower System. Energies 2017, 10, 2054. [CrossRef]

9. Hydrocen. Norwegian Research Centre for Hydropower Technology. Available online: https://www.ntnu.edu/hydrocen (accessed on 24 February 2021).

10. Norwegian Tunnelling Society. Norwegian Hydropower Tunnelling II, Publication 22. 2013. Available online: https://nff.no/wpcontent/uploads/sites/2/2020/04/Publication-22.pdf (accessed on 29 March 2021).

11. Panthi, K.K.; Basnet, C.B. State-of-the-art design guidelines in the use of unlined pressure tunnels/shafts for hydropower scheme. In Proceedings of the 10th Asian Rock Mechanics Symposium (ARMS10), Singapore, 29 October-3 November 2018; ISBN 978-981-11-9003-2.

12. Neupane, B.; Panthi, K.K.; Vereide, K. Effect of Power Plant Operation on Pore Pressure in Jointed Rock Mass of an Unlined Hydropower Tunnel: An Experimental Study. Rock Mech. Rock Eng. 2020, 53, 3073-3092. [CrossRef]

13. Bye, T.; Hope, E. Deregulation of electricity markets: The Norwegian experience. Econ. Political Wky. 2005, 40, 5269-5278.

14. L'Abée-Lund, J.H.; Otero, J. Hydropeaking in small hydropower in Norway-Compliance with license conditions? River Res. Aplic. 2018, 34, 372-381. [CrossRef]

15. National Instruments. Available online: https://zone.ni.com/reference/en-XX/help/371361R-01/lvanls/butterworth_filter/ (accessed on 29 March 2021).

16. Neupane, B.; Panthi, K.K. Evaluation on the effect of pressure transients on rock joints in unlined hydropower tunnel using numerical simulation. Rock Mech. Rock Eng. 2021. [CrossRef]

17. Palmstrøm, A.; Broch, E. The design of unlined hydropower tunnels and shafts: 100 years of Norwegian experience. Hydropower Dams 2017, 3, 1-9.

18. Kjørholt, H. Gas Tightness of Unlined Hard Rock Caverns. Ph.D. Thesis, Norges Tekniske Høgskøle (Now: Norwegian University of Science and Technology), Trondheim, Norway, 1991.

19. Goodman, R.E. Block theory and its applications. Geotechnique 1995, 45, 383-423. [CrossRef]

20. Preisig, G.; Eberhardt, E.; Smithyman, M.; Preh, A.; Bonzanigo, L. Hydromechanical Rock Mass Fatigue in Deep-Seated Landslides Accompanying Seasonal Variations in Pore Pressures. Rock Mech. Rock Eng. 2016, 49, 2333-2351. [CrossRef]

21. Bardal, R.; Bruland, A. Tunnel inspection in headrace tunnel of Ulset Hydropower Station 20.06.1986 (In Norwegian), Part of research project on" Rock support of Water Tunnels" for the Norwegian Hydropower Owners Association. Unpublished.

22. Forodden, H. Tunnel inspection-Headrace tunnel Ulset Hydropower Station 19.8.1992 (In Norwegian), for Sør-Trøndelag kraftselskap, KVO. Unpublished.

23. Døvle, L. Study on the long-term stability issues of the headrace tunnel of Ulset Hydropower Project. Master's Thesis, Norwegian University of Science and Technology, Trondheim, Norway, 2019.

24. Benson, R. Design of unlined and lined pressure tunnels. Tunn. Undergr. Space Technol. 1989, 4, 155-170. [CrossRef] 